\title{
Failure to escape shock following repeated exposure to inescapable shock
}

\author{
ROBERT A. ROSELLINI and MARTIN E. P. SELIGMAN \\ University of Pennsylvania, Philadelphia, Pennsylvania 19174
}

\begin{abstract}
Weiss, Glazer, and Pohorecky (1975) reported that repeated sessions of uncontrollable stressors fail to produce an escape learning deficit in the rat. This finding is unexpected in view of the often reported learned helplessness findings where a deficit in escape learning is found following a single session of uncontrollable shock. The discrepancy between these two sets of results may be due to procedural differences. The present experiment tests whether the usual parameters for producing learned helplessness in the rat produce escape deficits after repeated sessions. The results showed that an escape learning deficit is obtained, as expected, after repeated exposure to inescapable shock. The phenomenon reported by Weiss et al. (1975) appears to be different in kind from learned helplessness.
\end{abstract}

A rat exposed to a series of uncontrollable shocks subsequently fails to learn to escape shock in a novel situation (e.g., Maier, Albin, \& Testa, 1973; Maier \& Testa, 1975; Seligman \& Beagley, 1975; Seligman, Rosellini, \& Kozak, 1975). Maier, Seligman, and Solomon (1969), and more recently Seligman (1975), have theorized that this "learned helplessness" phenomenon results from the animal learning independence between its responding and shock. This learning is held both to reduce an animal's motivation to initiate responding and to produce associative interference. It is more difficult for such an animal to initiate responding and to later learn that his responding now produces reinforcement.

Recently. Weiss, Glazer, and Pohorecky (1975) proposed that learned helplessness findings may be accounted for in nonassociative terms. They propose a motor activation deficit hypothesis to account for these findings. This hypothesis is based on results which show that exposure to inescapable shock produces norepinephrine depletion in certain areas of the brain of the rat (Weiss, Stone, \& Harrell, 1970). and this depletion is said to lower the animal's motor activity level. So, when the animal fails to learn a response to terminate shock, it is not held to be due to associative interference but simply due to the animal's motor inability to make the response required. Weiss et al. (1975) performed a series of experiments to examine motor deficits following inescapable shock. In the most crucial experiment, Weiss et al. found no deficit in the learning of an escape response following repeated sessions of exposure to uncontrollable shock, whereas a deficit was obtained after a single session of

This research was supported by Postdoctoral Fellowship MH-00980-01 from the National Institute of Mental Health to the first author and Grant MH-19604 from the National Institute of Mental Health to the second author. Requests for reprints should be sent to Robert A. Rosellini, Department of Psychology, University of Pennsylvania, 3815 Walnut Street. Philadelphia. Pennsylvania 19174. uncontrollable shock. These results cannot be accounted for by a learned helplessness position since associative interference resulting from being exposed to a contingency of response-reinforcer independence should, if anything, be strengthened by repeated exposure to uncontrollable shock. However, the motor activation deficit hypothesis predicts such a reversal in the deficit since with repeated stress the noradrenergic system is held to recover.

There are sufficient procedural differences in the experiments reported by Weiss et al. (1975) and those reported by Seligman et al. (1975) and Maier et al. (1975) to warrant determining whether the different procedures may be producing two different phenomena. One critical difference may be the shock intensity levels used during inescapable shock in each of these experiments. Weiss et al. used a very high 4.0-mA shock, whereas Seligman et al. used $1.0 \mathrm{~mA}$. The purpose of the present experiment was to determine whether repeated exposure to $1.0-\mathrm{mA}$ inescapable shock under conditions which produce helplessness in the rat in our laboratory would produce no deficit. Such a result would indicate that the several recent reports of helplessness in the rat might be mediated by a norepinephrine-motor activation deficit. The opposite result would indicate that Weiss and his colleagues may be studying a phenomenon different in kind from that under investigation in our laboratory.

\section{METHOD}

\section{Subjects}

The subjects in this experiment were 24 male Holtzman rats. approximately 90 days old at the start of the experiment. They were housed in individual cages and had continuous access to food and water. All animals were run during the light phase of the $12-\mathrm{h}$ light/12-h dark cycle.

\footnotetext{
Apparatus

Four operant chambers were used for both the inescapable shock training and escape testing. Each chamber was $30.5 \mathrm{~cm}$ long.
} 


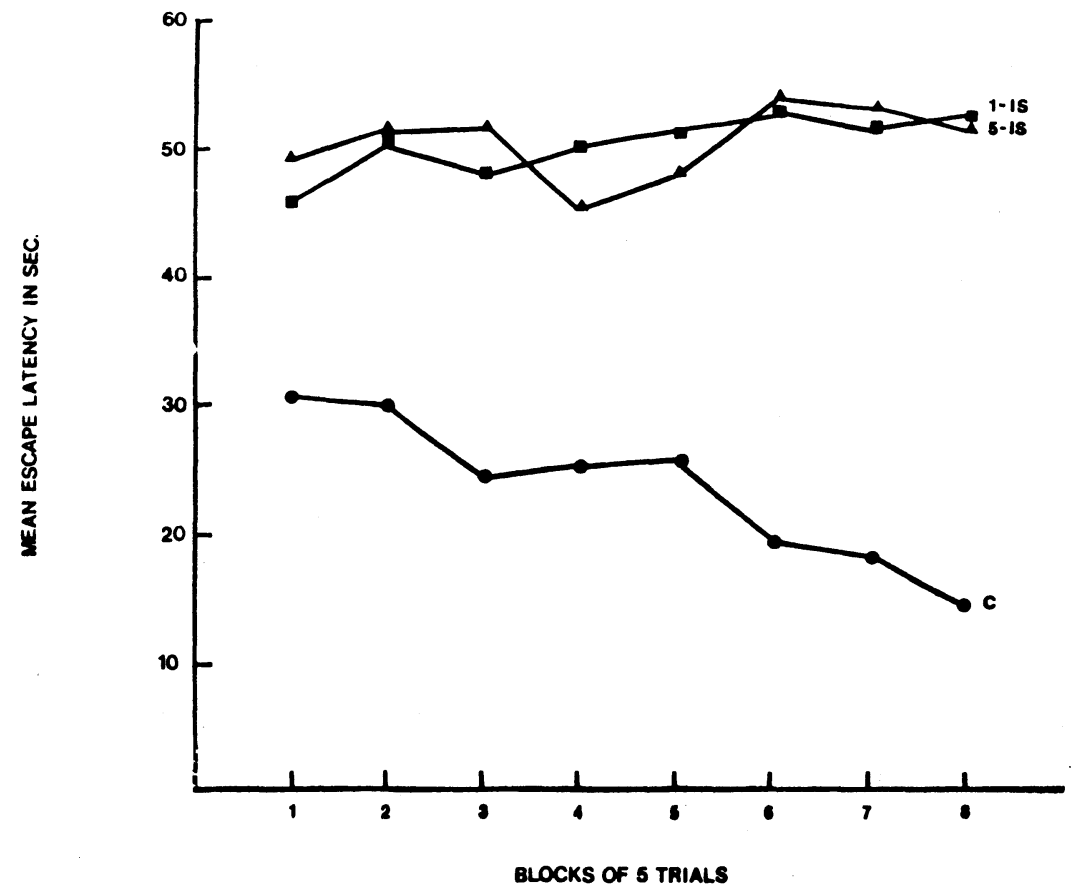

Figure 1. Mean shock eacape latencies in seconds for the groups exposed to 15 sesalon of inescapable shock (15-IS), one session (1-IS), and the no-schok control (C) as a function of blocks of five trials.

$20.3 \mathrm{~cm}$ wide, and $19 \mathrm{~cm}$ high. Two walls and the ceiling of each chamber were constructed of clear Plexiglas. The other walls were constructed of plywood. The grid floor of the chamber consisted of stainless steel grids $.64 \mathrm{~cm}$ in diam, spaced $1.27 \mathrm{~cm}$ apart. A lever $(7.6 \times 3.8 \mathrm{~cm})$ was centered on the front wall $7.6 \mathrm{~cm}$ above the grid floor. The lever was not present in the chamber during the inescapable shock phase of the experiment. A constant current shock source was used to deliver $1.0 \mathrm{~mA}$ of shock to the animal. The chambers were housed in sound-attenuating containers equipped with a houselight and masking noise. All programming and recording equipment was housed in a separate room.

\section{Procedure}

The rats were assigned to each of the three treatment groups $(\mathrm{N}=8$ ) on the basis of their body weights so that the mean body weight for each group was approximately equal $(359,361$, and $364 \mathrm{~g}$ ). A subcutaneous pin electrode was mounted on the upper part of each rat's back and the backs of the rats were shaved. Shock was delivered through this pin electrode and the grid floor of the chamber. The rats in the first group (15-IS) subsequently received 15 sessions of inescapable shock with one session per day. Each session consisted of 80 trials of $15 \mathrm{sec}$ of $1.0 \mathrm{~mA}$ inescapable shock presented on a variable-interval 1-min schedule. On Day 15, the rats in the second group (1-IS) were given a single session of 80 trials of inescapable shock. The third groud was used as a control. This group (C) was placed in the chambers for 15 sessions for an identical period of time; however, it was never given shock during training. All rats were also weighed prior to each session.

On Day 16, all animals were tested for their ability to learn a leverpress response to terminate shock. Three leverpresses (Fixed Ratio 3) were required to terminate shock. Testing was conducted for 40 trials. On each trial, a 1.0-mA shock was presented for a maximum of $60 \mathrm{sec}$, or until the rat escaped by depressing the lever. The escape latency for each trial was recorded for each rat.

\section{RESULTS}

Both groups exposed to inescapable shock (Groups 15-IS and 1-IS) failed to learn to escape shock. The control group learned the FR-3 barpress response to terminate shock and escaped efficiently throughout the 40 testing trials. Figure 1 shows the mean escape latencies for each of the three groups as a function of blocks of five trials. A 3 by 8 analysis of variance showed the escape latencies for the three groups to be significantly different, $F(2,21)=7.64, \quad p<.01$. Newman-Keuls post-hoc tests showed Group C animals to be reliably faster escapers than either Group 15-IS or 1-IS animals $(p<.01)$, which did not differ from each other $(p>.10)$.

Weight differences were also obtained between the groups. All groups increased in body weight over days, but Group 15-IS showed a slower increase than Groups 1-IS and C. A 3 by 15 analysis of variance performed as a function of groups and days on the animal's body weight resulted in a significant groups factor, $F(2,21)=7.77, \quad p<.01$, days factor, $F(14,294)=203.71, p<.01$, and Group by Days interaction, $F(28,294)=9.94, p<.01$. The interaction resulted from Groups $\mathrm{C}$ and 1-IS gaining equivalent weight, while Group 15-IS gained weight more slowly. On Day 1 of the experiment, the mean body weights for Groups 1-IS, 15-IS, and C were $364 \mathrm{~g}, 359 \mathrm{~g}$, and $361 \mathrm{~g}$, respectively. On Day 15, their mean weights were $428 \mathrm{~g}, 404 \mathrm{~g}$, and $425 \mathrm{~g}$, respectively.

\section{DISCUSSION}

The escape results are consistent with an associative interference hypothesis but not with a norepinephrine-motor deficit hypothesis. Rats exposed to repeated sessions of inescapable shock failed to escape shock on the subsequent test, like rats exposed to a single session of inescapable shock. Control animals not previously exposed to shock learned to barpress to terminate shock. A learned 
helplessness position suggests that repeated exposure to inescapable shock should produce a more profound interference with the animal's ability to escape than one session of inescapable shock. This possibility cannot be evaluated in the present experiment because of a ceiling effect. Animals given both one and 15 sessions of inescapable shock failed to escape on most trials.

Procedural discrepancies between our experiment and that of Weiss et al. (1975) may account for the different effect produced by repeated exposure to inescapable shock. One major procedural difference was that we used a moderate-intensity $1.0-\mathrm{mA}$ shock whereas Weiss et al. used a high-intensity 4.0-mA shock. We know our deficit to be produced by uncontrollability and not trauma per se, since groups equivalent to 1-IS but given escapable shock do not develop escape deficits (Hannum, Rosellini, \& Seligman, 1975; Seligman \& Beagley, 1975; Seligman, Rosellini, \& Kozak, 1975). Weiss' deficit, on the other hand, may result from trauma per se, since they report no groups which receive $4.0 \mathrm{~mA}$ of escapable shock; indeed, this is such an intense shock that we doubt rats would readily learn to escape it. In addition, there are several discrepancies in the results obtained with our procedures and those reported by Weiss et al. They report a deficit in a rat's ability to learn to cross from one side of a two-way shuttlebox to the other to escape shock following 4.0-mA inescapable shock. Maier, Albin, and Testa (1973) and Maier and Testa (1975) reported a deficit in the animal's ability to learn to cross twice (FR-2) in a two-way shuttlebox following 1.0-mA inescapable shock, but neither Maier's group nor ours has ever obtained a deficit when only one crossing (FR-1) is required to immediately terminate shock. Similarly, we have not been able to obtain an escape deficit if a single barpress (FR-1) is required to terminate shock. But a deficit is obtained when three barpresses are required (Seligman \& Beagley, 1975). In addition, Weiss et al. (1975) report that their deficit dissipates in approximately $2 \mathrm{~h}$, whereas we have found no dissipation in time of the deficits produced by inescapable shock in adult rats (Seligman, Rosellini, \& Kozak, 1975). And, indeed, the deficit persists from shortly after weaning to adulthood in the rat (Hannum, Rosellini, \& Seligman, 1975).

Other grounds make a norepinephrine-motor deficit hypothesis of the sort suggested by Weiss et al. (1975) and Anisman (1975) seem insufficient to account for the learned helplessness results obtained in Maier and our laboratories. Rats exposed to inescapable shock fail to escape with even simple (FR-1) motor responses when the association is difficult (delay of shock termination). However, they escape well with difficult motor responses (FR-2 or FR-3) when a simple associative task (feedback provided) is used (Maier \& Testa, 1975). Uncontrollable delivery of food, which presumably does not deplete norepinephrine, interferes with later learning to escape shock (Rosellini, Bazerman, \& Seligman, in preparation). Prior or subsequent exposure to escapable shock (Seligman, Rosellini, \& Kozak, 1975) or controllable food (Rosellini, 1976) reverses the escape deficits, but there is no apparent reason that such procedures should modify norepinephrine deficits.

We find it necessary to postulate learning of independence between reinforcers and responses to account for these results. Our view may in the long run not be incompatible with the norepinephrine view since it is possible that catecholamine changes may be one mediator of cognitive changes. A simple transient norepinephrine-motor deficit, however, is wholly inadequate.

In conclusion, the escape deficits reported by Weiss et al. (1975) differ considerably from the learned helplessness phenomenon obtained by Maier and in our laboratory: it dissipates in time, it is produced by very high shock levels, it lacks control groups for escapable shock, and it is reversed by repeated exposure to the uncontrollable stressor. Using procedures which produce a phenomenon which does not seem to dissipate in time, with moderate shock intensities, and which has controls for escapability, we find that repeated sessions of inescapable shock produce consistent failure to escape. We suggest therefore that our phenomenon is learned helplessness, caused by learning that shock and responding are independent; whereas Weiss' phenomenon is different in kind-possibly a transient, norepinephrine mediated, stress phenomenon.

\section{REFERENCE NOTES}

1. Hannum, R. D., Rosellini, R. A., \& Seligman, M. E. P. Learned helplessness in the rat: Retention and immunization. Developmental Psychology, 1975, submitted.

2. Rosellini, R. A. Inescapable shock interferes with the acquisition of a free appetitive operant. Journal of Experimental Psychology: Animal Behavior Processes, 1976, submitted.

3. Rosellini, R. A., Bazerman, M., \& Seligman, M. E. P. Transfer of learned helplessness from an appetitive to an aversive context. In preparation.

\section{REFERENCES}

Anisman, H. Time-dependent variations in aversively motivated behaviors: Nonassociative effects of cholinergic and catecholamine activity. Psychological Review, 1975, 82. 359-385.

Maier, S. F., Albin, R. W., \& Testa, T. J. Failure to learn to escape in rats previously exposed to inescapable shock depends on the nature of the escape response. Journal of Comparative and Physiological Psychology, 1973, 85. 581-592.

Maier, S. F., Seligman, M. E. P., \& Solomon, R. L. Pavlovian fear conditioning and learned helplessness. In B. A. Campbell and R. M. Church (Eds.), Punishment and aversive behavior. New York: Appleton-Century-Crofts, 1969.

MAier, S. F., \& Testa, T. J. Failure to learn to escape by rats previously exposed to inescapable shock is partly produced by associative interference. Journal of Comparative and Physiological Psychology, 1975, 88, 554-564.

Seligman, M. E. P. Helplessness. San Francisco: Freeman, 1975.

Seligman, M. E. P., \& Beagley, G. Learned helplessness in the rat. Journal of Comparative and Physiological Psychology, $1975,88,534-541$.

Seligman, M. E. P., Rosellini, R. A., \& Kozak, M. J. Learned helplessness in the rat: Time course, immunization, and reversibility. Journal of Comparative and Physiological Psychology, 1975, 88, 542-547.

Weiss, J. M., Glazer, H. I., \& Pohorecky, L. A. Coping behavior and neurochemical changes: An alternative explanation for the original "learned helplessness" experiments. In G. Serban \& A. Kling (Eds.), Relevance of the psychopathological animal model to the human. New York: Plenum Press. 1975, in press.

Weiss, J. M., Stone, E. A., \& Harrell, N. Coping behavior and brain norepinephrine level in rats. Journal of Comparative and Physiological Psychology, 1970, 72. 153-160.

(Received for publication November 10, 1975.) 